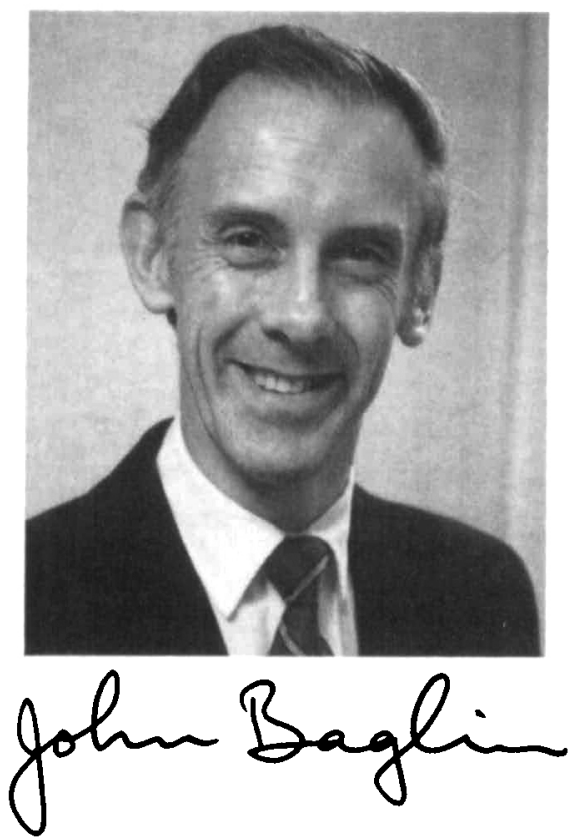

What should the Materials Research Society plan to achieve in the years ahead? How should the Society itself and its agenda of activities look 5 to 10 years from now? What positive steps can we be taking now and in the immediate future to make sure that these visions become reality?

The Long Range Planning Committee is asked to grapple with such far-reaching questions of critical significance for MRS. Its special mission is to look beyond the excitement and details of the next meeting, and "think big." This Committee is asked to gather the information needed and assemble responsible recommendations on major growth strategies. These recommendations can form the basis for the MRS Council to set policies for the future and to implement them in a coordinated way. It is this Committee, more than any, whose focus should be on the "big picture" of materials research, in which MRS provides increasingly effective support and stimulus for the materials research community of the future, and continues to earn its position of high respect as a leader among technical and professional organizations.

A good try for lofty goals, but how can this Committee of well-intentioned scientists actually generate plans of real practical value to the Society? This question was addressed clearly by the Long Range Planning Committee during the 1988 MRS Spring Meeting in Reno. Among other business, the Committee began to prepare an up-to-date 5-year and 10-year Society plan for discussion at the upcoming MRS Fall Meeting in Boston. Representatives of our activities in meeting planning, technical programs, publica-

\title{
Shaping Our Future
}

tions, education, corporate interactions, external affairs, international liaison, member services and headquarters operations have been asked to prepare projections and proposals for future MRS development. Bob Chang is now assembling the initial responses, so that the overall balance of the proposed MRS evolution can be studied. Then will come the most exciting and difficult step-coordinating those plans in greater detail so that, together, they make a strong, integrated plan which could become the guideline for future policy and action

Note my use of the word "guideline." It is nobody's intention that this exercise generate inflexible constraints for the Society. I am convinced that a special spark of spontaneity and innovation has been the key to MRS's dynamic growth and professional success. Our readiness to try new ideas, adapt to new circumstances, and start fresh projects has, without doubt, been the hallmark of MRS's development. Our new Long Range Plan must recognize the value of this unique flexibility and spirit of enterprise, and make room for them; it must be subtly prepared to nurture such qualities, not inhibit them.

Now for the punch line. I want your interest and participation in this Society project. The Materials Research Society exists, after all, to serve individual members and associates such as you, besides addressing the broader global aims. It is extremely important that your individual voices be heard, that your ideas and opinions be expressed so that you can directly help determine the future shape of your Society. Your input can be a valuable resource during the preparation of these plans.

Please write your comments succinctly and send them to Kathy Taylor (chair of the Long Range Planning Committee) or to me, preferably before August 1, so they can be considered in the current planning cycle. Even better, send a copy of your comments as a "Letter to the Editor" of the MRS BULLETIN. Open, ongoing discussion of future MRS priorities and possibilities in the BULLETIN can enhance your active role in shaping our destiny, and at the same time provide an extremely valuable sampling of ideas and opinions for use by the planning committees. Your letters will be truly welcome.

To provoke your responses, let me ask some questions (with the firm disclaimer that these do not necessarily reflect any policy decisions currently under serious study).

- Should MRS hold more meetings? Should we experiment with new meeting formats? What is the ideal meeting size?

- How important are the short courses? Should there be more? Should MRS develop new programs to serve the materials education community?

- What about public awareness...should MRS initiate media projects to inform and update the lay public on materials questions? Should MRS develop advocacy positions on public policy?

- How should the MRS publications portfolio develop? Should it include different products, or include special fields such as databases and software?

- In what ways might MRS strengthen the Corporate Affiliate program? How could the value of the equipment exhibit be enhanced? Should MRS member services be expanded?

On scanning this list, I am led to a key general question-what balance of activities should prevail in MRS? It would be easy, in the joy of inventing attractive fresh projects, to overlook the fundamental activity which has earned MRS its primary success and member support-that of running the best and most fruitful technical meetings in the field. Should our excursions into other interesting ventures be purposely limited in number and extent in order to preserve a focus of attention and effort in the business of holding first-class technical meetings? Or should we try to encompass every activity whereby we believe we can offer significant support to the materials community?

There are no "right" or "wrong" answers, only opinions. I think MRS should develop some criteria for evaluating lateral ventures. A basic criterion could be that each activity or service is one MRS can offer in a particularly effective way, because of our philosophy, our interdisciplinary structure, our experience, or the nature of our membership. What's your opinion?

John E.E. Baglin, IBM Almaden Research Center, K34/802, Harry Road, San Jose, CA $95120-6099$

Kathleen C. Taylor, GM Research Laboratories, Physical Chemistry Department, Warren, MI 48090 


\section{S-800 Hitachi Field Emission Scanning Electron Microscope}

- Operation optimized by CPU automation

- Best s/n ratio

- Best depth of field
- Highest resolution

- Beam monitor for noise-free images

- Wide range of operating voltages

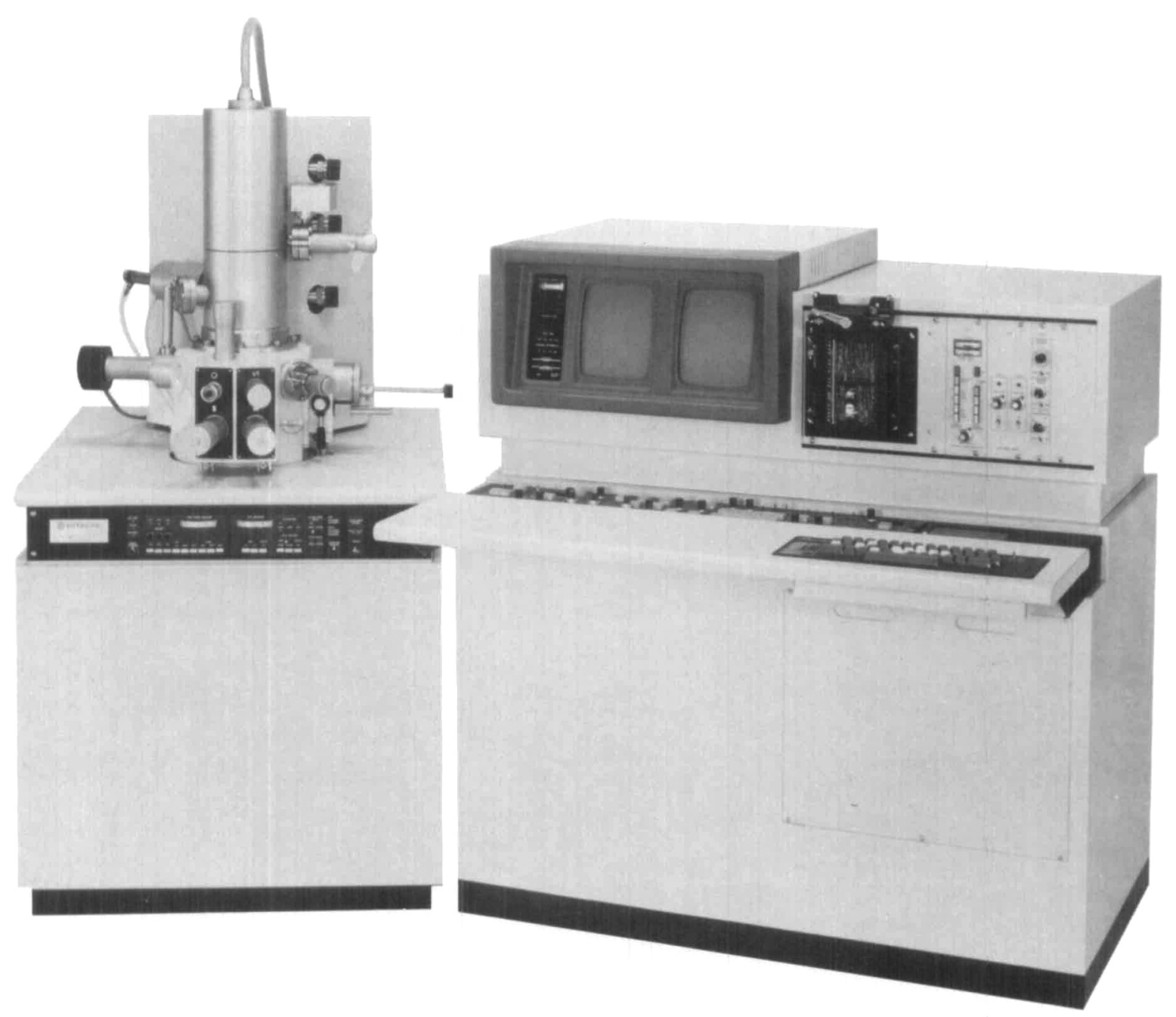

More than 20 years experience with field emission systems

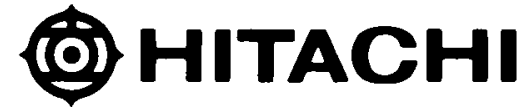

SCIENTIFIC INSTRUMENTS Nissei Sangyo America, Ltd.
460 E. Middlefield Road, Mountain View, CA 94043, (415) 961-0461 2096 Gaither Road, Rockville, MD 20850, (301) 840-1650 